Original Article

\title{
Effects of a multifactorial fall prevention program on balance, gait, and fear of falling in post-stroke inpatients
}

\author{
Younuk Jung, PT, MSc ${ }^{1)}$, Kyeongbong Lee, PT, MSc ${ }^{1)}$, Seonhae Shin, MA ${ }^{2)}$, \\ WANhEe LEe, PT, $\mathrm{PhD}^{1)^{*}}$ \\ 1) Graduate School of Physical Therapy, Sahmyook University: 815 Hwarang-ro, Nowon-gu, Seoul \\ 139-742, Republic of Korea \\ 2) Department of English, Sahmyook University, Republic of Korea
}

\begin{abstract}
Purpose] This study investigated the effects of a multifactorial fall prevention program on balance, gait, and fear of falling in stroke patients. [Subjects] Twenty-five stroke patients were divided randomly into multifactorial fall prevention program group $(\mathrm{n}=15)$ and control treadmill group $(\mathrm{n}=10)$. [Methods] All interventions were applied for $30 \mathrm{~min}$, five times per week, for five weeks. The fall prevention program included interventions based on the "Step Up to Stop Falls" initiative and educational interventions based on the Department of Health guidelines. For those in the treadmill group, the speed was increased gradually. The Korean falls efficacy scale and Korean activities-specific balance confidence scale were used to assess fear of falling. To assess balance and walking ability, the Korean performance-oriented mobility assessment scale and the 10-m and 6-minute walk tests were used. [Results] The fall prevention program interventions were found to be very effective at improving gait, balance, and fear of falling compared with the treadmill intervention and therefore seem appropriate for stroke patients. [Conclusion] A multifactorial fall prevention program is effective at improving balance, gait ability, and fear of falling. It is a more specific and broad intervention for reducing falls among inpatients in facilities and hospitals.

Key words: Multifactorial fall prevention, Balance, Gait ability
\end{abstract}

(This article was submitted Jan. 21, 2015, and was accepted Mar. 7, 2015)

\section{INTRODUCTION}

Stroke manifestations vary depending on the lesion site and severity. Development of hemiplegia causes difficulties in weight bearing on the affected side and maintaining balance, both of which are required for correct posture. An imbalanced posture results in instability during standing, muscle weakness, and a limited range of motion. These features are predictive of an increased likelihood of falls and decreased gait ability ${ }^{1)}$. The risk of falls may increase after a patient has experienced one fall, even in the absence of physical damage, because of an increased fear of falling ${ }^{2)}$. Schoenfelder et al. suggested that fall prevention education and muscle strengthening can decrease the fear of falling and risk of falls ${ }^{3}$. A fall prevention program that includes balance, muscle strengthening, and flexibility training is effective for improving gait, balance ability, and perception of the risk of falling ${ }^{4}$. Because falls have multiple causes, multifactorial interventions including patient education

*Corresponding author. Wanhee Lee (E-mail: whlee@syu. ac.kr)

C2015 The Society of Physical Therapy Science. Published by IPEC Inc. This is an open-access article distributed under the terms of the Creative Commons Attribution Non-Commercial No Derivatives (by-ncnd) License $<$ http://creativecommons.org/licenses/by-nc-nd/3.0/> . and improvement of muscle strength, balance, and gait are required for fall prevention. However, most fall prevention programs consist of a single item, and because falls are influenced by physical, psychological, environmental, and social factors, an effective fall prevention program would include exercise and educational interventions ${ }^{5}$. Although many studies have reported ways to prevent falls ${ }^{6,7)}$, the subjects in these investigations were elderly people in the community, and only a single program was applied. Fall prevention interventions have to begin in high-risk facilities and hospitals ${ }^{8)}$. Therefore, the purpose of this study was to study baseline data and decrease the risk of falls using a multifactorial fall prevention program (MFPP) in post-stroke patients.

\section{SUBJECTS AND METHODS}

Thirty patients (16 males, 14 females) who had experienced a stroke within the previous year at the $M$ hospital in Seoul-Si were included. Based on previous studies, the following inclusion criteria were used: age $<65$ years, able to walk independently, Korean mini-mental state examination (MMSE-K) score $>24$, and able to understand the study procedures and communicate ${ }^{9)}$. The exclusion criteria were medication use, which can influence gait ability and balance, visual deficits, and vestibular impairment. This study used a randomized two-group pretest-posttest design. Subjects were randomly allocated to the MFPP group ( $\mathrm{n}=15, \mathrm{MFPG})$ 
1866 J. Phys. Ther. Sci. Vol. 27, No. 6, 2015

Table 1. Multifactorial fall prevention program

\begin{tabular}{|c|c|c|c|}
\hline Exercise type & & & Time (sets/duration) \\
\hline \multirow{10}{*}{ Exercise } & $\begin{array}{l}\text { Strengthening interven- } \\
\text { tion }\end{array}$ & Calf stretching & $30-60 \sec 5$ repetitions \\
\hline & & Heel/Toe raise & $5-10 \mathrm{sec}$ \\
\hline & & Marching & Floor/Stairs \\
\hline & & SLR: forward, side, backward & $5-10 \mathrm{sec}, 10$ repetitions, 3 sets \\
\hline & & Leg curl & In sitting on chair \\
\hline & Balance intervention & Ankle ROM exercise & Draw A to $\mathrm{Z}$ \\
\hline & & Standing on air cushion & Up and down the leg alternately \\
\hline & & Diagonal movement exercise & In holding both hands with trunk rotation \\
\hline & Flexibility intervention & Standing with head movement & General standing $30 \mathrm{sec}$ Tandem standing $30 \mathrm{sec}$ \\
\hline & & Standing on balance pad & Eye open/close \\
\hline Education & $\begin{array}{l}\text { Regulation of fall } \\
\text { Environmental factor }\end{array}$ & Before starting exercise for 5 minutes & \\
\hline $\begin{array}{l}\text { General physical } \\
\text { therapy }\end{array}$ & $\begin{array}{l}\text { NDT } \\
\text { PNF }\end{array}$ & $\begin{array}{l}\text { General stretching and strengthening } \\
\text { Static and dynamic balance training }\end{array}$ & 2 times/day, 5 days/week \\
\hline
\end{tabular}

Table 2. Treadmill exercise program

\begin{tabular}{lccc}
\hline Exercise & Treadmill & $\begin{array}{c}\text { Increase the speed by } 0.4 \mathrm{~km} / \mathrm{h} \text { per week if pos- } \\
\text { sible independent walking }\end{array}$ & $\begin{array}{c}\text { Exercise stopped in cases of fatigue, dyspnea on } \\
\text { exertion, or on patients' request }\end{array}$ \\
\hline $\begin{array}{l}\text { General physical } \\
\text { therapy }\end{array}$ & NDT & $\begin{array}{c}\text { General stretching and strengthening } \\
\text { Static and dynamic balance training }\end{array}$ & 2 times/day, 5 days/week \\
\hline
\end{tabular}

NDT: neurodevelopmental technique; PNF: proprioceptive neuromuscular facilitation

or treadmill exercise group ( $\mathrm{n}=15, \mathrm{TEG})$. Five patients were excluded from the MFPG. From the TEG, 1 male and 3 female patients were excluded due to discharge before completion of the experiment, and 1 female patient was excluded for personal reasons. The randomization was generated by a computer drawing lots. All study procedures were explained to the subjects prior to participation, and written informed consent was obtained from all subjects. This study was approved by the Sahmyook University Institutional Review Board.

Before the intervention program, the subjects' gait speed and endurance were assessed using the Korean performanceoriented motor assessment (POMA-K) scale ${ }^{10)}, 10-\mathrm{m}$ walk test, and 6-min walk test. The Korean falls efficacy scale ${ }^{11)}$ (FES-K) and Korean activities-specific balance confidence ${ }^{12)}$ (ABC-K) scale were used to assess the balance self-assurance of the patients. The multifactorial exercise program included education regarding fall prevention, neuro-developmental treatment (NDT), and training for muscle strengthening, balance, and flexibility. It was carried out for $30 \mathrm{~min}$ per day, five times a week, over a 5-week period. The treadmill exercise program included NDT and treadmill exercise, with a $0.4 \mathrm{~km} / \mathrm{h}$ increase in speed per week. The details of both exercise programs are described in Tables 1 and 2.

The SPSS version 19.0 statistical software was used for all analyses. Statistics were used to describe patient characteristics after confirming that the data were normally distributed. A comparison of the general characteristics was performed using the independent t-test or $\chi^{2}$ test. Pre- and post-data were analyzed using the paired t-test to test differences within the groups. Scheffe's post-hoc test was used to test the significance of differences between the groups. A significance level of 0.05 was used for all measurements.

\section{RESULTS}

The general characteristics of the subjects are presented in Table 3. No significant differences in general characteristics were observed between the MFPG and TEG (age, 49.9 years vs. 53.2 years; height, $168.1 \mathrm{~cm}$ vs. $164.8 \mathrm{~cm}$; body weight, $64.7 \mathrm{~kg}$ vs. $62.3 \mathrm{~kg}$ ).

Differences in pre- and post-test values within and between the groups are summarized in Table 4. The POMA-K scores were significantly higher in the MFPG $(p<0.01)$ and significantly different between the groups $(\mathrm{p}<0.05)$. Both groups showed significant improvements in the $10-\mathrm{m}$ walk test (MFPG, $\mathrm{p}<0.01$; TEG, $\mathrm{p}<0.05$ ) and gait speed, but there was no difference between the groups. The MFPG showed a significant improvement in the 6-min walk test score $(\mathrm{p}<0.001)$, and the difference was significantly greater than that in the TEG. In addition, the FES-K score significantly improved in the MFPG only $(\mathrm{p}<0.05)$, with a significant difference between groups $(\mathrm{p}<0.05)$. The $\mathrm{ABC}-\mathrm{K}$ score either $(\mathrm{p}<0.05)$. 
Table 3. General characteristics

\begin{tabular}{lcc}
\hline Parameter & MFPG & TEG \\
\hline Gender & & \\
Male/Female (\%) & $10 / 5(66.7 / 33.3)$ & $5 / 5(50.0 / 50.0)$ \\
Age, years & $47.9 \pm 10.6$ & $53.2 \pm 12.3$ \\
Height, cm & $165.1 \pm 7.7$ & $164.8 \pm 10.8$ \\
Weight, kg & $64.7 \pm 8.4$ & $62.3 \pm 8.4$ \\
Disease cause & & \\
Infarction /Hemorrhage & $8 / 7(53.3 / 46.7)$ & $5 / 5(50.0 / 50.0)$ \\
Affected side & & \\
Right/Left (\%) & $10 / 5(66.7 / 33.3)$ & $4 / 6(40.0 / 60.0)$ \\
Disease duration (months) & $8.02 \pm 2.9$ & $6.22 \pm 2.2$ \\
MMSE-K & $26.7 \pm 2.3$ & $26.3 \pm 1.8$ \\
\hline Values are expressed as n (\%) or mean \pm SD. & \\
MFPG: multifactorial program group; TEG: treadmill exercise group; MMSE-K: mini- \\
mental state examination-Korean
\end{tabular}

Table 4. Comparison of POMA-K, 10-m walk test, 6-minute walk test, FES-K, and ABC scale-K

\begin{tabular}{lcccc}
\hline & \multicolumn{2}{c}{ MFPG $(\mathrm{n}=15)$} & \multicolumn{2}{c}{ TEG $(\mathrm{n}=10)$} \\
\hline & Pretest & Posttest & Pretest & Posttest \\
\hline POMA-K & $19.67(6.04)$ & $23.80(5.17)^{* *}$ & $17.30(4.24)$ & $17.40(5.58)$ \\
10-m walk test (m/s) & $0.48(0.23)$ & $0.65(0.28)^{* *}$ & $0.43(0.26)$ & $0.55(0.29)^{*}$ \\
6-minute walk test (m/s) & $0.49(0.25)$ & $0.60(0.26)^{* *}$ & $0.40(0.23)$ & $0.44(0.27)$ \\
FES-K & $59.00(21.03)$ & $72.93(15.61)^{* *}$ & $57.30(19.32)$ & $55.50(25.67)$ \\
ABC scale-K & $47.35(18.14)$ & $62.40(17.28)^{* *}$ & $39.45(19.78)$ & $40.70(25.50)$ \\
\hline
\end{tabular}

Values are expressed as mean (SD). Within group differences ${ }^{*} \mathrm{p}<0.05,{ }^{* *} \mathrm{p}<0.01$

MFPG: multifactorial program group; TEG: treadmill exercise group; POMA-K: performance-oriented motor assessment-Korean; FES-K: fall efficacy scale-Korean; ABC scale-K: activities-specific balance confidence scale-Korean

\section{DISCUSSION}

This study aimed to investigate the effects of an MFPP comprised of exercise and educational interventions for improving balance, gait, as well as fear of falling, and to provide a suitable approach for use of a fall prevention program in stroke inpatients. Guidelines for fall prevention in the United States and Britain suggest that a multifactorial program, involving exercise and educational interventions, is more effective than a single intervention, and that fall prevention programs have to be focused on physiological and psychological factors such as fear of falling ${ }^{5}$. Because exercise interventions alone cannot improve FES scores, exercise and educational intervention are needed for individuals at a high risk for falls ${ }^{3)}$. Tinetti studied the benefits of multifactorial interventions for muscle strengthening and improvement of balance and self-confidence in comparison to those of a single intervention. They recommend an MFPP, because physical and occupational therapists alone cannot control falls or reduce the fear of falling ${ }^{13)}$

In this study, the MFPG showed significant improvements in physical activity and FES-K scores, as shown in other

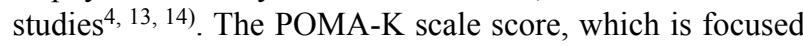
on mobility, significantly increased in the MFPG $(p<0.01)$, and this result indicates a greater increase than that seen in previous studies ${ }^{15)}$. For gait ability, the $10-\mathrm{m}$ walk test and 6-min walk test were used in this study. The MFPG had a significantly increased $10-\mathrm{m}$ walk test score $(\mathrm{p}<0.01)$ and 6 -min walk test score $(\mathrm{p}<0.01)$, but the TEG showed a significant increase only in the $10-\mathrm{m}$ walk test score $(\mathrm{p}<0.05)$. Because fall prevention exercise interventions increase balance ability and strengthen muscles, the risk of falls is decreased by $15-20 \%{ }^{16)}$. In particular, the 6 -min walk test score, used to assess functional capacity in older adults ${ }^{17}$, significantly increased in the MFPG. Therefore, it can be seen that an MFPP positively influences walking ability and aerobic capacity.

Batchelor et al. suggested that an MFPP improves balance $(p<0.01)$, gait speed $(p<0.01)$, and the FES score $(p<0.05)$ in stroke patients returning home after rehabilitation ${ }^{18)}$. Their results show that exercise and educational interventions have to be used together to reduce the fear of falling. Our study demonstrates that an MFPP was effective at improving FES-K scores $(p<0.05)$, and the treadmill exercise was not $(\mathrm{p}>0.05)$. In addition, the FES-K score was significantly different between the groups $(\mathrm{p}<0.05)$. The ABC-K scale, a more objective evaluation of the fear of falling, showed the same results as the FES-K (MFPG $\mathrm{p}<0.01$, TEG $\mathrm{p}>0.05$ ). In other words, exercise intervention improved balance and gait ability, and educational intervention improved the psy- 
chological aspect of the fear of falling. Cumming et al. reported that home visits can prevent falls among older people who are at increased risk of falling. However, this effect may not be the result of improved balance and strength alone, but also due to a decreased fear of falling ${ }^{8}$. The risk of falling within 12 months in those with a decreased FES score was half that in patients whose FES score had not decreased ${ }^{9)}$. Therefore, interventions for fall prevention need to begin at hospital facilities, and programs must consist of a variety of approaches. Using the ABC-K scale with the FES scale is an efficient method of evaluating the fear of outdoor activities as well as indoor activities ${ }^{18)}$.

While this study demonstrates the effectiveness of an MFPP, it has some limitations. First, although balance, gait ability and FES scores significantly improved after the MFPP, it can be difficult to prove the frequency of falls using these factors alone; the validity of this study is therefore limited. Second, a reduction in fall frequency is the eventual goal, but an intervention period of 5 weeks is too short to allow an assessment of this factor. It is therefore suggested that further studies include longer intervention and followup periods.

\section{REFERENCES}

1) Nyberg L, Gustafson Y: Patient falls in stroke rehabilitation. A challenge to rehabilitation strategies. Stroke, 1995, 26: 838-842. [Medline] [CrossRef]

2) Sangpring P, Vongsirinavarat M, Hiengkaew V, et al.: Development of a geriatric fear of falling questionnaire for assessing the fear of falling of Thai elders. J Phys Ther Sci, 2012, 24: 359-364. [CrossRef]

3) Schoenfelder DP, Van Why K: A fall prevention educational program for community dwelling seniors. Public Health Nurs, 1997, 14: 383-390. [Medline] [CrossRef]

4) : Guideline for the prevention of falls in older persons. American Geriatrics Society, British Geriatrics Society, and American Academy of Orthopaedic Surgeons Panel on Falls Prevention. J Am Geriatr Soc, 2001, 49: 664-672. [Medline]
5) Panel on Prevention of Falls in Older Persons, American Geriatrics Society and British Geriatrics Society: Summary of the Updated American Geriatrics Society/British Geriatrics Society clinical practice guideline for prevention of falls in older persons. J Am Geriatr Soc, 2011, 59: 148-157. [Medline] [CrossRef]

6) Kim WJ, Chang M, An DH: Effects of a community-based fall prevention exercise program on activity participation. J Phys Ther Sci, 2014, 26: 651-653. [Medline] [CrossRef]

7) Ming Huo HM: The effectiveness of a simple approach to the assessment of the risk of fall in the elderly-probe reaction time and dispersion of the time for a single step during marking time. J Phys Ther Sci, 2007, 18: 181185

8) Cumming RG, Thomas M, Szonyi G, et al.: Home visits by an occupational therapist for assessment and modification of environmental hazards: a randomized trial of falls prevention. J Am Geriatr Soc, 1999, 47: 1397-1402. [Medline]

9) Cumming RG, Salkeld G, Thomas M, et al.: Prospective study of the impact of fear of falling on activities of daily living, SF-36 scores, and nursing home admission. J Gerontol A Biol Sci Med Sci, 2000, 55: M299M305. [Medline] [CrossRef]

10) Tinetti ME: Performance-oriented assessment of mobility problems in elderly patients. J Am Geriatr Soc, 1986, 34: 119-126. [Medline]

11) Tinetti ME, Richman D, Powell L: Falls efficacy as a measure of fear of falling. J Gerontol, 1990, 45: 239-243. [Medline] [CrossRef]

12) Powell LE, Myers AM: The activities-specific balance confidence (ABC) scale. J Gerontol A Biol Sci Med Sci, 1995, 50A: M28-M34. [Medline] [CrossRef]

13) Tinetti ME: Multifactorial fall-prevention strategies: time to retreat or advance. J Am Geriatr Soc, 2008, 56: 1563-1565. [Medline] [CrossRef]

14) Diener DD, Judith M: Impact of a multifactorial fall prevention program upon falls of older frail adults attending an adult health day care center. Top Geriatr Rehabil, 2005, 21: 247-257. [CrossRef]

15) Suhrie EM, Hanlon JT, Jaffe EJ, et al.: Impact of a geriatric nursing home palliative care service on unnecessary medication prescribing. Am J Geriatr Pharmacother, 2009, 7: 20-25. [Medline] [CrossRef]

16) Barnett A, Smith B, Lord SR, et al.: Community-based group exercise improves balance and reduces falls in at-risk older people: a randomised controlled trial. Age Ageing, 2003, 32: 407-414. [Medline] [CrossRef]

17) Bohannon RW: Six-minute walk test: a meta-analysis of data from apparently healthy elders. Top Geriatr Rehabil, 2007, 23: 155-160. [CrossRef]

18) Batchelor FA, Hill KD, Mackintosh SF, et al.: Effects of a multifactorial falls prevention program for people with stroke returning home after rehabilitation: a randomized controlled trial. Arch Phys Med Rehabil, 2012, 93: 1648-1655. [Medline] [CrossRef] 